\title{
LACTIC DEHYDROGENASE AND OTHER ENZYMES IN THE MOUSE UTERUS DURING THE PERI- IMPLANTATION PERIOD OF PREGNANCY
}

\author{
KATHLEEN HALL \\ Department of Physiology, Medical School, University of Birmingham, \\ Birmingham, B15 2 TJ
}

(Received 3rd Fuly 1972)

Summary. A histochemical investigation of enzyme activities in the uterine endometrium of mice from Days 4 to 8 of the first pregnancy is described, Day 1 being the day on which a copulation plug appeared in the vagina. The timing and cellular location of changes in reactions for lactic dehydrogenase ( $\mathrm{LDH})$ are compared with those for 5 '-nucleotidase (AMPase), $\alpha$-glucan phosphorylase, nicotinamide adenine dinucleotide(NAD)-diaphorase, succinic dehydrogenase (SDH), adenosine triphosphatase (ATPase) and alkaline phosphatase (APase), and of glycogen and lipids. The appearance of APase, deposition of glycogen and changes in LDH or phosphorylase in the antimesometrial stromal cells at future implantation sites were preceded by the disappearance of AMPase from these cells before implantation on Day 5. This, in turn, may retard the dephosphorylation of adenosine-5'monophosphate and make more of this substance available for activation of phosphorylase in these cells. Increased reactions for LDH first appeared early on Day 5 (before implantation) in the cells of the APasefree primary decidua. These were accompanied by increased reactions for SDH but preceded the first appearance of glycogen in the same cells. Later on Day 5 and throughout Day 6, there was further strengthening and spread of increased LDH activity accompanied in the same cells by increased phosphorylase, reappearance of strong AMPase, increased $\mathrm{SDH}$, and by deposition of glycogen. The patterns of the rise and fall of glycogen in the decidua and of the accompanying changes in enzyme activities on these days support the concept of a metabolically active tissue with a high rate of glycogen turnover. The disappearance of glycogen from the cells of the antimesometrial decidua on Day 7, with continued increase in LDH, phosphorylase and AMPase, suggest that glycolysis is in the ascendant here, while the accompanying accumulation of glycogen in the 'glycogen wings' and peripheral stroma, without marked increase in $\mathrm{LDH}$, indicates that this is an area of glycogen storage. The use of urea and pyruvate to inhibit, respectively, the $\mathrm{M}$ - and $\mathrm{H}$-type subunits of $\mathrm{LDH}$ showed a great predominance of $\mathrm{M}$ subunits throughout the endometrium. This would enable the tissue to 
derive energy from anaerobic pathways when oxygen is deficient. Distribution and changes in NAD-diaphorase paralleled those of LDH, and changes in SDH also showed some parallel. There was a reciprocal relationship between distribution of $\mathrm{LDH}$ and that of lipids in the decidual cells. The timing of the disappearance of ATPase and periodic acidSchiff reactivity from endometrial capillaries was compared with that of the other changes and the implications are discussed, particularly in relation to recent reports of variations in uterine oxygen tension in the rat during the same period. No demonstrable changes were observed in the endometrium between decidua.

\section{INTRODUCTION}

In earlier papers (Hall, 1968, 1971), changes were described in the activities of adenosine triphosphatase, $5^{\prime}$-nucleotidase, acid phosphatase and phosphorylase and in properties of capillary basal laminae in the uterine endometrium of mice during pregnancy. These changes all took place within the peri-implantation period and were evidently of significance for the siting of implantation, metabolism of the decidua or nutrition of the embryo.

Histochemically demonstrable changes in activities of two other enzymes have now been studied during the same period of pregnancy-lactic dehydrogenase, which like phosphorylase has an important rôle in glycolysis, and succinic dehydrogenase, a key enzyme in the Krebs' cycle. These enzymes have been investigated in the rat by both histochemical and biochemical techniques, particularly by Christie $(1966,1967)$ and Yochim and his co-workers (Yochim \& Mitchell, 1968; Clark \& Yochim, 1971; Yochim, 1971; Yochim \& Clark, 1971a, b), but only Wong \& Dickson (1969) appear to have made a histochemical study of these and other dehydrogenases in relation to implantation in the mouse. The present study revealed a number of features which were not described by Wong \& Dickson (1969).

In order to compare more precisely the timing, location, progress and possible significance of the alterations in the dehydrogenase activities with those of the other enzymes already described, techniques for all these enzymes, and also for localization of glycogen and lipids, were repeated on the uteri used in the present experiments. A 'sandwich' method of mounting serial sections enabled techniques for a number of enzymes, and for glycogen and lipids, to be carried out at any level of the uterus, permitting very close cell-with-cell comparisons.

\section{MATERIALS AND METHODS}

Virgin female albino mice of Parkes' strain, from a closed but not inbred colony, were mated when approximately $2 \frac{1}{2}$ months old. Day 1 of pregnancy was the day on which a seminal plug was found in the vagina. Mice were killed, by a blow on the head, at various times on each day from Days 4 to 8 . All animals killed on Day 5 were given an injection into a tail vein of $0.25 \mathrm{ml}$ of a $1 \%$ aqueous solution of Pontamine blue $15 \mathrm{~min}$ before death. The discrete blue-staining bands which appeared in the uterine horns indicated the sites at which blasto- 
cysts had implanted or would do so. A few mice, killed on Days 4 to 7 , were injected subcutaneously with $0.1 \mathrm{mg}$ colchicine $2 \mathrm{hr}$ before death. Pieces of horn were immediately frozen onto a cryostat holder, using a Slee $\mathrm{CO}_{2}$ bench freezer. Those taken on Day 5 and onwards included the whole of a blue-stained area or an implantation swelling, together with a little of the adjacent portion of the horn. The whole of the stained area or of the swelling, together with some of the neighbouring tissue, was sectioned transversely and serially (unfixed) in a cryostat. The sections, $12 \mu \mathrm{m}$ thick, were mounted two or three at a time, in rotation on a series of cover-slips, one for each test or its specificity control. When each had received its first quota of sections, the sequence was repeated on the same slips as many times as necessary until the desired length of horn had been sectioned. In this way, up to ten different techniques-tests and controlscould be applied simultaneously to the same piece of uterus, and comparable sections at any particular level were easily identified. For mice killed before Day 5, a piece from the middle of the horn was chosen and a similar sandwich section-mounting technique used. (For one mouse killed on Day 4, the uterus was sectioned at fourteen different levels along the length of one horn-no variations in the patterns of enzyme activities were found at the different levels.) For mice killed on Days 4 to 6 inclusive, the unused parts of the uterus were fixed in Lison's 'Gendre fluid' (picro-formol-acetic), embedded in paraffin wax, and sectioned serially in the longitudinal plane for presence of unimplanted embryos or as a check on the stage of implantation.

The techniques used for enzyme activities, with times of incubation in parentheses, were as follows.

Alkaline phosphatase. Gomori's (1952) calcium-cobalt-sulphide method (10 $\mathrm{min}$ ), after fixation of sections for $30 \mathrm{~min}$ in cold acetone.

5'-Nucleotidase. Wachstein \& Meisel's (1957) lead method, as modified by Barron \& Boshes (1961) (20 min), after fixation of sections in cold acetone for $10 \mathrm{~min}$; for control sections, glycerophosphate was substituted for adenosine- $5^{\prime}$ monophosphate (Pearse, 1968).

Acid phosphatase. Gomori's (1952) lead phosphate method, as modified by Burstone (1962) (20 to $30 \mathrm{~min}$ ), with $0.01 \mathrm{M}$-sodium fluoride added as an inhibitor to the control substrate medium.

Succinic dehydrogenase. Pearse (1960) using Nitro-BT as the hydrogen acceptor $(20 \mathrm{~min})$. Paired sets of sections were incubated with and without preliminary immersion for $10 \mathrm{~min}$ in cold acetone for removal of fatty deposits; both sets were counterstained with Oil Red 0 for localization of, or check on removal of, neutral lipids. Control sections were incubated (a) without substrate and (b) with addition of $0.05 \mathrm{M}$-sodium malonate as inhibitor.

Lactic dehydrogenase. Nitro-BT method (Pearse, 1960) (20 min) with and without preliminary immersion in acetone and with Oil Red 0 as a counterstain. Specificity controls included omission of substrate or of the cofactor, nicotinamide adenine dinucleotide, or both, and addition of $10^{-1} \mathrm{M}$-pyruvate as inhibitor. The technique of Jacobsen (1969), which includes high concentrations of Nitro-BT and also of polyvinyl alcohol in the incubating fluid to reduce diffusion, and of phenazine methasulphate (PMS) to render lactic dehydrogenase independent of endogenous diaphorase, was also used on representative 
sections. For some sections, urea $\left(10^{-3 \cdot 25} \mathrm{M}\right)$ or pyruvate $\left(10^{-4} \mathrm{M}\right)$ were used to inhibit, respectively, the M- and $\mathrm{H}$-subunits of lactic dehydrogenase (Jacobsen, 1969).

Nicotinamide adenine dinucleotide diaphorase. Nitro-BT method (Pearse, 1960) (20 min), with sodium lactate as the substrate.

Phosphorylase. A modification of Takeuchi \& Kuriaki's (1953) method for $\alpha$-glucan phosphorylase (Pearse, 1972), with ethanol added to the substrate mixture (1 hr $15 \mathrm{~min}$ ).

Glycogen. Periodic acid-leucofuchsin after fixation of sections for $30 \mathrm{~min}$ in ethanol; specificity was checked by incubation of control sections with amylase.

Adenosine triphosphatase. Lead method of Wachstein \& Meisel (1956) as modified in Pearse (1960).

\section{Terminology}

The following abbreviations are used throughout. Enzymes: for colour reactions obtained after incubation of sections in the appropriate substrate mixture and believed to signify specific activity of the appropriate enzyme: APase-alkaline phosphatase; ATPase-adenosine triphosphatase; AMPase-an enzyme with optimum activity with adenosine-5'-monophosphate as substrate, and believed to be 5'-nucleotidase although final proof of this has not been obtained in decidual cells; AcPase-acid phosphatase; $\mathrm{SDH}$ - succinic dehydrogenase; LDH--lactic dehydrogenase; NAD —nicotinamide adenine dinucleotide (coenzyme I); diaphorase-enzyme which oxidizes reduced coenzyme I.

\section{RESULTS}

The word 'inactive' in the text should be taken as signifying a level of activity below that which could be demonstrated by the histochemical technique used, not necessarily complete absence. Similarly, 'lipid-free' or 'glycogen-free' means absence of material which could be demonstrated by the histochemical techniques used. Unless otherwise stated, LDH and SDH are described or illustrated in sections from which lipids had been removed by immersion in cold acetone before incubation with the substrates.

\section{Day 4}

In the endometrium of all mice killed on Day 4 and in the non-decidualized endometrium on Days 5 to 8 , the reactions obtained were so similar that sections from one animal killed on Day 4 can be regarded as typical. The reactions are summarized in Table 1 and some are illustrated in Pl. 1, Figs 1 to 3. Reactions for ATPase and periodic acid-Schiff's reagent (PAS) in capillary endothelium, and for AMPase in stroma and AcPase in glandular epithelium, are also illustrated in Hall $(1968,1971)$. The strong LDH reaction in the cytoplasm of luminal epithelial cells (PI. 1, Figs 1 and 2) was accompanied by a weaker reaction for SDH, by a reaction for AMPase at the luminal borders, traces of AcPase and no APase. In the glandular epithelium, the reactions for both LDH (Pl. 1, Fig. 3) and SDH were strong, and there was considerable AcPase but no AMPase or APase reaction. Both epithelia contained considerable lipid but no 
demonstrable glycogen or phosphorylase. In the stromal cells, the reaction for $\mathrm{LDH}$ (PI. 1, FIgs 2 and 3) was less strong than for SDH; both reactions were much weaker than in the epithelial cells, and the depth of colour did not vary in different parts of the endometrium. Of the phosphatases, only AMPase was strong (at cell borders), no reactions being obtained for the others. Neither glycogen nor lipids were demonstrated. In capillaries, LDH (PI. 1, Figs 2 and 3), SDH and strong ATPase, but not APase, were present; ATPase was located mainly at the basal surface, and the basal laminae were strongly PAS-reactive.

Table 1. Glycogen, lipids and enzyme activities in endo? metrial tissues on Day 4 and in non-decidualized parts of uteri on Days 5 to 8 of pregnancy in mice

\begin{tabular}{l|c|c|c|c}
\hline \multirow{2}{*}{$\begin{array}{c}\text { Substance or } \\
\text { enzyme activity }\end{array}$} & \multicolumn{4}{|c}{ Tissue component of endometrium } \\
\cline { 2 - 5 } & $\begin{array}{c}\text { Luminal } \\
\text { epithelium }\end{array}$ & $\begin{array}{c}\text { Glandular } \\
\text { epithelium }\end{array}$ & $\begin{array}{c}\text { Stromal } \\
\text { cells }\end{array}$ & $\begin{array}{c}\text { Capillary } \\
\text { endothelium }\end{array}$ \\
\hline Glycogen & 0 & 0 & 0 & 0 \\
Lipid & +++ & ++ & 0 & 0 \\
APase & 0 & 0 & 0 & 0 \\
AcPase & $(0)$ & ++ & 0 & 0 \\
ATPase & $+0)$ & 0 & 0 & ++ \\
AMPase & ++ & 0 & ++ & 0 \\
SDH & + or ++ & ++ & + or ++ & + \\
LDH & +++ & +++ & + & + \\
Phosphorylase & 0 & 0 & 0 & 0 \\
\hline
\end{tabular}

0 : none demonstrable; $(0):$ traces;,,$++++++:$ little, moderate or considerable amounts. For abbreviations in Column 1, see p. 82.

\section{Day 5}

Mice were killed at various times between 09.30 and 15.30 hours. In our colony, kept under conditions of $12 \mathrm{hr}$ light/12 hr dark, the time at which the mice mate varies considerably. Hence, animals on Day 5 were not grouped by time of autopsy but from microscopic analysis of factors such as area of APase in the stroma, glycogen deposition, mitotic activity, blastocyst attachment or stage of implantation, and progress of decidualization.

One of the earliest stages at which Pontamine blue-located 'sensitive areas' were sectioned for enzyme tests is illustrated in Pl. 1, Figs 4, 5 and 6 and Pl. 2, Fig. 7. Paraffin wax-embedded sections of this uterus contained unimplanted blastocysts in contact with an intact epithelium on a strongly PAS-reactive basal lamina. In test sections cut in the cryostat at the level of the implantation chamber, a narrow band of APase-free subepithelial primary decidual cells (Pl. 2, Fig. 7) showed small increases in depth of colour reactions for LDH (Pl. 1, Figs 4 and 5) and SDH. Sparse granules of glycogen were detected by the PAS reaction in some of these cells and a few glycogen-containing leucocytes were also present between the cells. At the periphery of this zone, APase (P1. 2, Fig. 7) had appeared in a small area of antimesometrial stromal cells and in a few subepithelial stromal cells in the mesometrial quadrant; these cells showed no increase in $\mathrm{LDH}$ or SDH. Adenosine triphosphatase had disappeared from the endothelium of subepithelial capillaries around the implantation chamber, 
and AMPase reactions were much weakened in an area of antimesometrial stroma. Lipid droplets were sparse in the APase-inactive, SDH- and LDHactive primary decidua but in the surrounding stroma, the cells contained many Oil Red-stained lipid droplets onto each of which had precipitated dark blue granules of formazan (Pl. 1, Fig. 6). The peripheral stromal cells did not contain lipid droplets and showed no increase in LDH. No change was detected in the enzyme activities of the luminal or glandular epithelium, except for a possible increase in AcPase in the former.

Some mice were examined on Day 5 at an even earlier stage, when APase was only just detectable in a few scattered cells of the future secondary decidua, but reactions for both $\mathrm{LDH}$ and SDH were already increased in the primary decidual cells.

At the most advanced stage investigated on Day 5 , the luminal epithelium had largely broken down within the implantation chamber, the blastocyst had started to implant, and there was heavy deposition of glycogen in the stromal

\section{EXPLANATION OF PLATES 1 TO 3}

Abbreviations: APase, alkaline phosphatase activity; LDH, lactic dehydrogenase activity; SDH, succinic dehydrogenase activity; AMPase, 5'-nucleotidase activity; AMP, adenosine $5^{\prime}$-monophosphate. All figures are whole or parts of transverse sections of the uterine horns of mice killed on the days stated of their first pregnancy (times in parentheses). The sections were cut in a cryostat from unfixed frozen tissue, and were mounted and processed for demonstration of the respective enzyme activity as described on p. 81 .

\section{PLATE 1}

FIG. 1. Day 4 (12.20 hours). Lactic dehydrogenase activity, after removal of lipids with acetone. There is a strong reaction throughout the cytoplasm of the luminal and glandular epithelia and a much weaker reaction in the cytoplasm of the stromal cells. The small, more strongly reactive areas dotted throughout the endometrium are capillaries. All nuclei were non-reactive. $\times 85$.

FIG. 2. The same section as Fig. 1. Luminal epithelium at right, stroma in centre, circular muscle at left. The section shows a strong reaction in the epithelial cytoplasm, and a moderate reaction in stromal cells and in the sarcoplasm of the muscle cells. One arteriole (bottom left corner) and three capillaries cut longitudinally are present in the muscle layer. The tiny vacuoles in epithelial cells are the sites of fat droplets, which stained with Oil Red 0 in an adjacent section not processed through acetone. Fat droplets were not seen in stromal cells. $\times 350$.

Fig. 3. Same section as Figs 1 and 2, showing glands in the endometrial stroma and a strong reaction in glandular cytoplasm; the small vacuoles are lipid droplets. The reaction in the stromal cells is like that in the subepithelial endometrium in Fig. 2. An arteriole (A, arrow) cut longitudinally, left of centre, shows reactions in the endothelial cytoplasm and muscle sarcoplasm. Capillaries around the glands (arrows) show reaction in the endothelial cytoplasm. $\times 350$.

FIg. 4. Day 5 (14.40 hours); killed 15 min after an intravenous injection of Pontamine blue. There were six (left) and seven (right) blue-staining bands evenly spaced across the horns. The section, which was cut across a blue band at the level of the implantation chamber, shows the reaction for $L D H$ after removal of lipids with acetone. The primary decidual cells around the chamber show a slight increase in reaction-colour. The reactions in the rest of the stroma, capillaries, luminal and glandular epithelia are unchanged from Day 4. (Paraffin wax-embedded sections showed blastocysts in the uterine lumen attached to the epithelium, which was still intact). $\times 85$.

Fig. 5. Section of the same uterus as Fig. 4, showing the LDH reaction after removal of lipid. The subepithelial primary decidual cells gave a stronger reaction than the surrounding stromal cells. $\times 350$.

FIG. 6. Neighbouring section to that in Fig. 5, and the same area, showing the LDH reaction without preliminary removal of lipids, counterstained with Oil Red 0 . Dark blue formazan granules precipitated onto each Oil Red-stained fat droplet are considered to be an artifact not indicating true $\mathbf{L D H}$. Lipid/formazan granules were sparse in the primary decidua but very numerous in the subjacent stromal cells. $\times 350$. 
PLATE 1
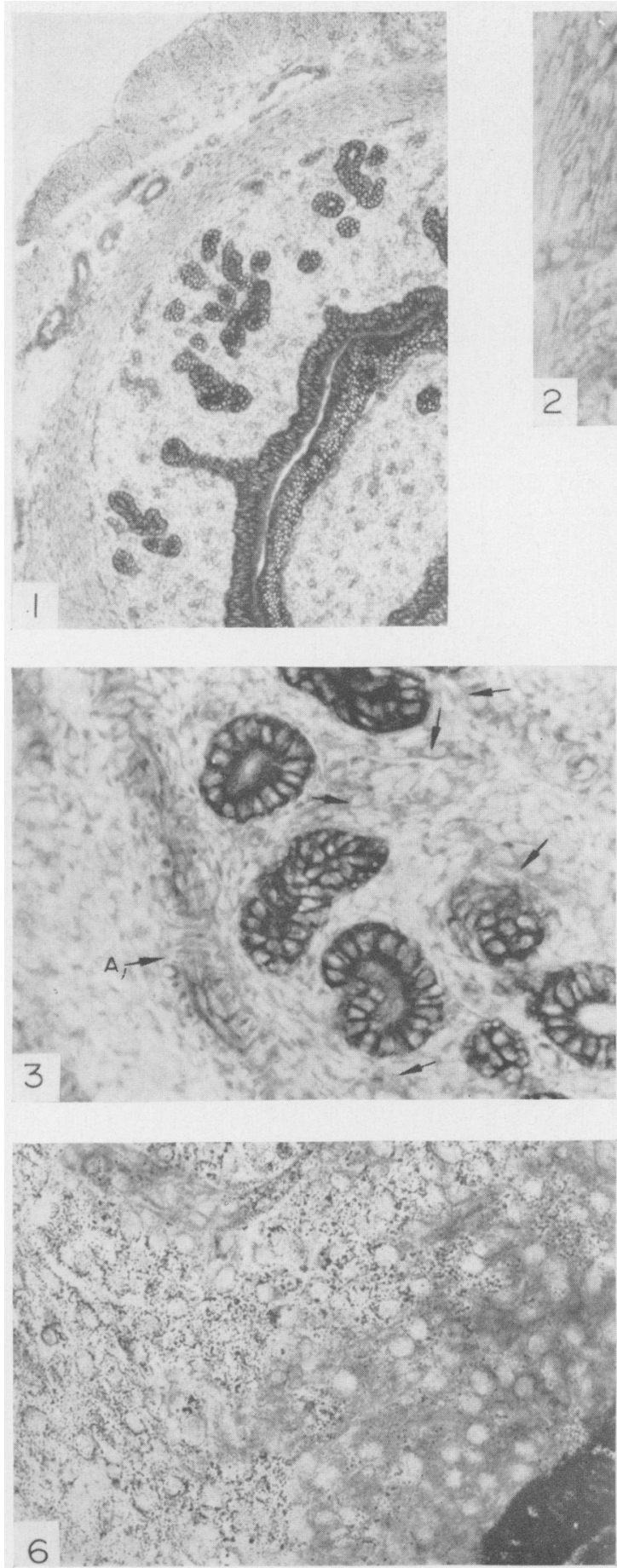
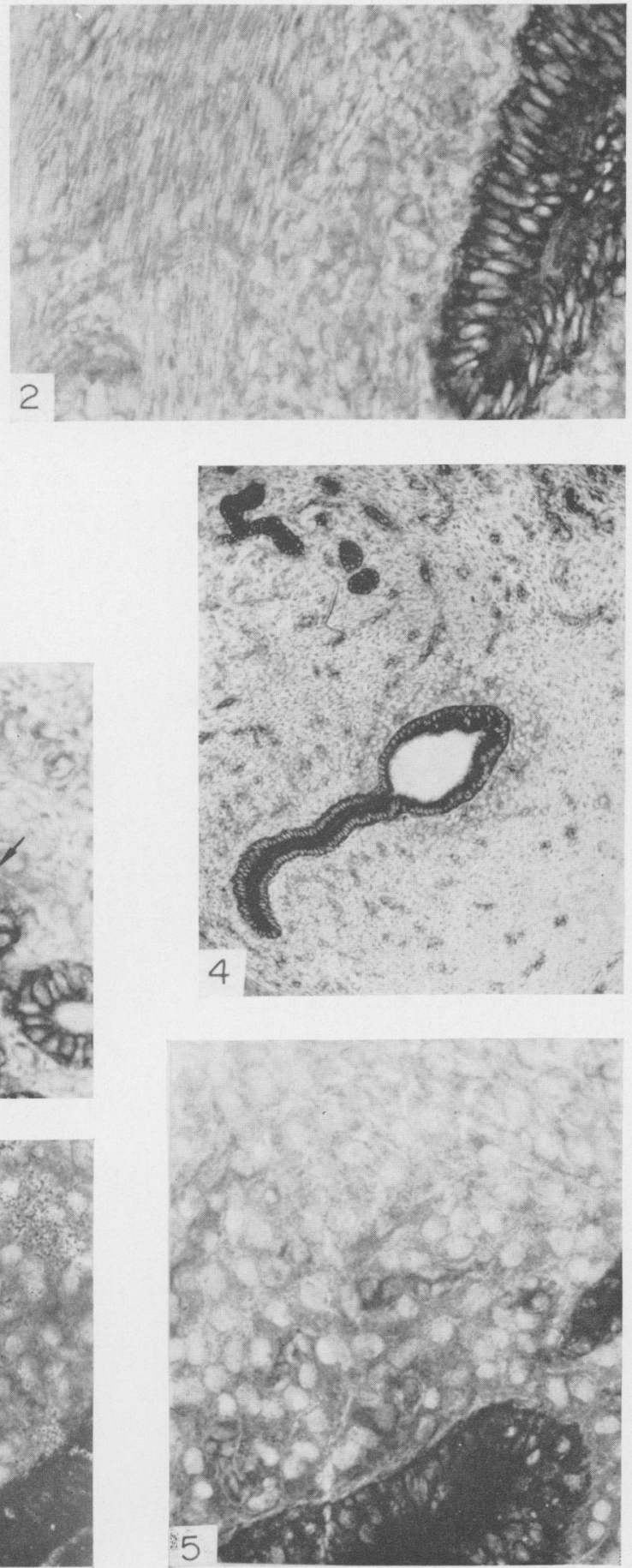
PLATE 2
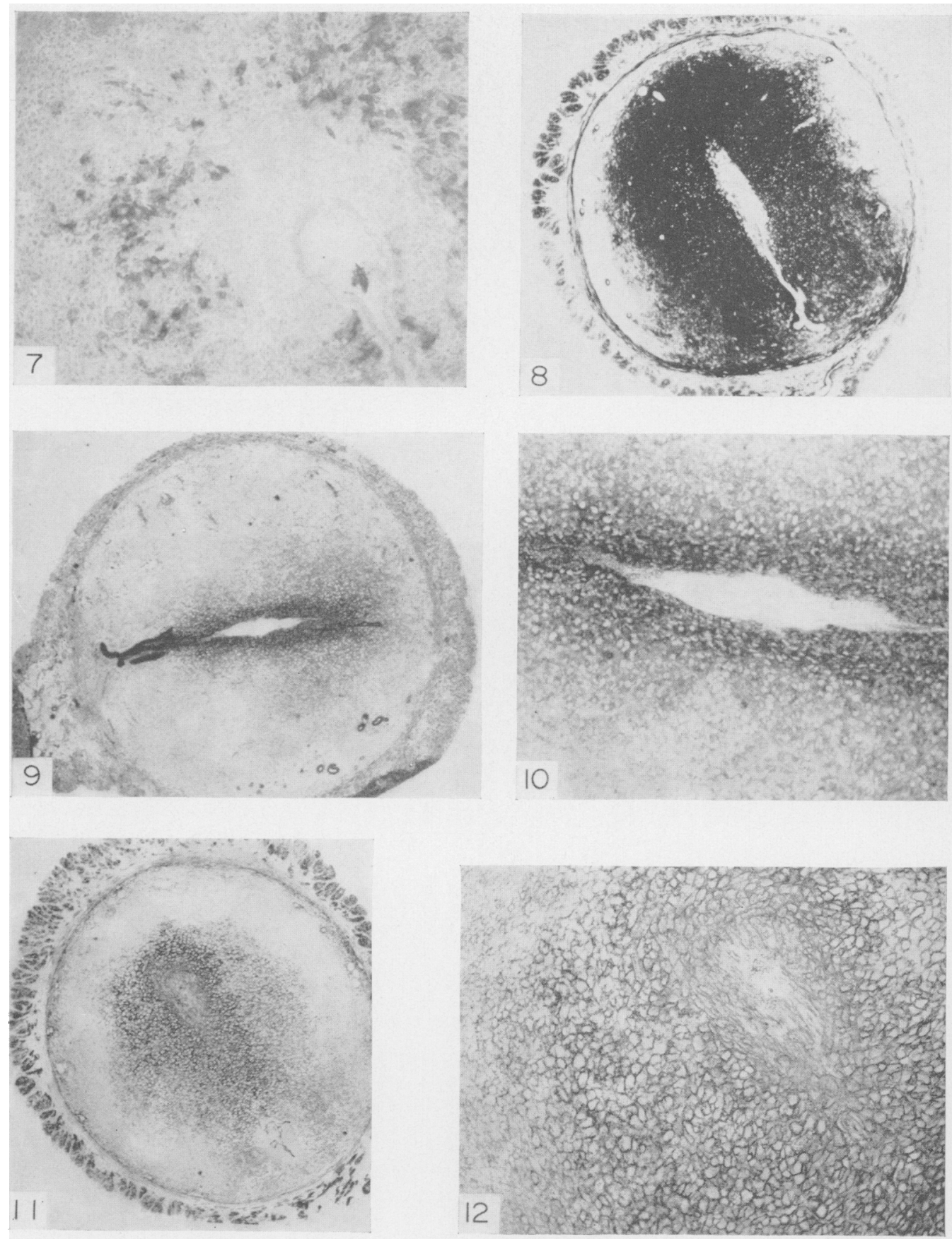

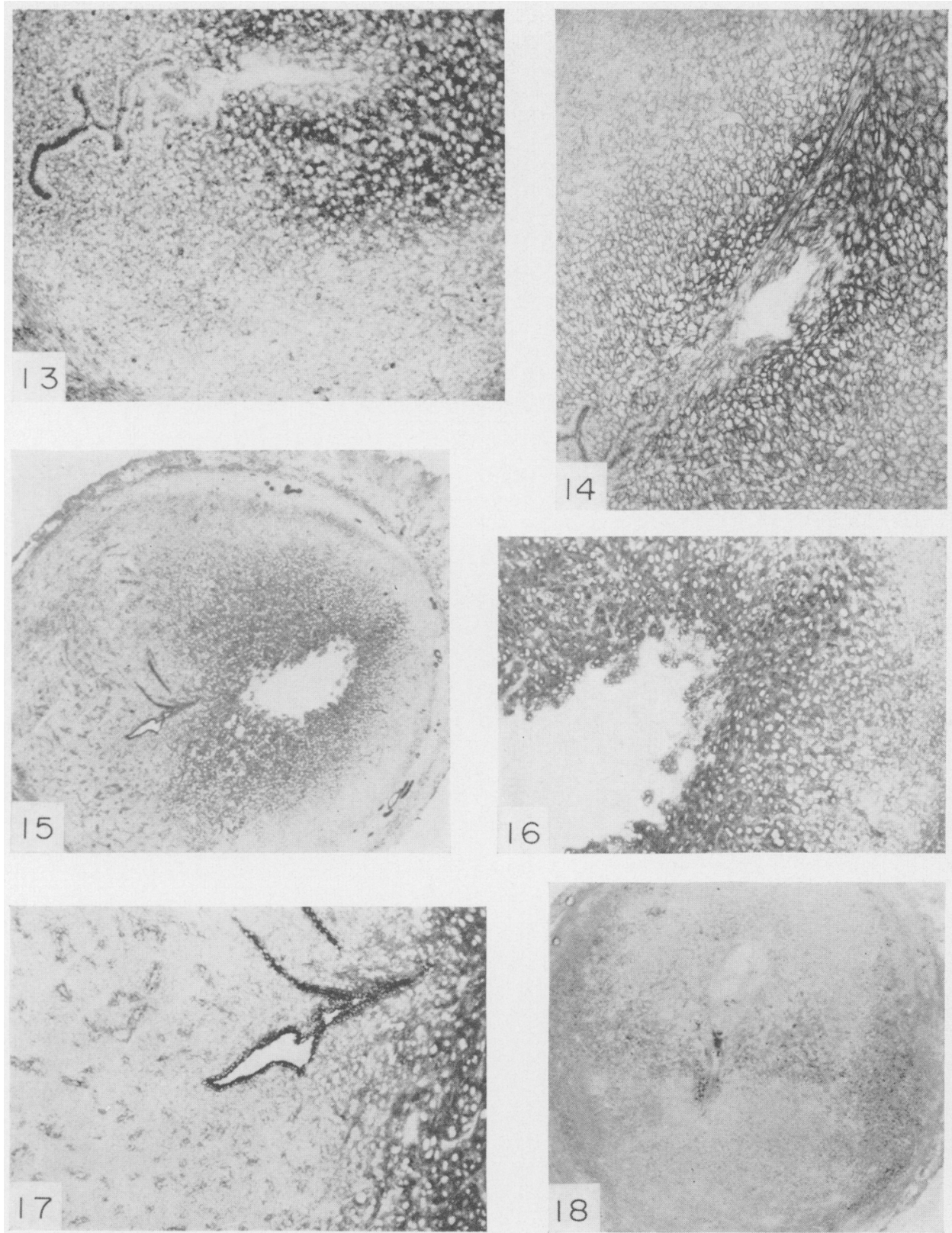


\section{PLATE 2}

Fic. 7. The same uterus as in Figs 4 to 6 , sectioned at the same level and incubated for APase. The reaction in the stroma is confined to a few cells around the periphery of the non-reactive primary decidua, and to a few subepithelial cells in the mesometrial quadrant. $\times 85$.

Fig. 8. Day 6 (10.20 hours). There were seven (left) and one (right) implantation swellings in the horns. The section which was cut across the approximate centre of the implantation site and incubated for APase shows the extent (black) of decidualization. Peripheral non-decidualized stroma, the remnants of glands within that area, and the luminal epithelium outside the decidua gave no reaction, but arterioles in the peripheral stroma showed APase activity. $\times 21$.

FIG. 9. A neighbouring section to that in Fig. 8, incubated for LDH after removal of lipids. The decidual cells around the site of implantation (antimesometrial and lateral) show greatly increased activity. There was no increase in colour-reaction in the remainder of the stroma. The luminal epithelium mesometrial to the decidua and the remaining glands still show strong activity. $\times 21$.

FIg. 10. Part of the same section as in Fig. 9, showing that the reaction in the decidual cells is located throughout the cytoplasm. $\times 85$.

Frg. 11. The same uterus as in Fig. 10. The section which was cut at an angle which was slightly tangential to the implanted embryo and incubated for AMPase shows a strong reaction in the central decidual cells, a weaker reaction in the outer part of decidua and almost no reaction in the peripheral stromal cells, except in a narrow zone of nondecidualized cells at the extreme periphery of the endometrium. In the mesometrial quadrant, there is a non-reactive area of stromal cells surrounding the luminal epithelium. A reaction is seen at the border of the luminal but not of the glandular epithelium. (Control sections incubated in a mixture in which glycerophosphate was substituted for AMP suggested that some of the activity in the decidual cells may be due to a nonspecific phosphatase.) $\times 21$.

Fig. 12. The same section as in Fig. 11, showing that the reaction in the decidual cells is located at the cell borders. $\times 85$.

\section{PLATE 3}

FIG. 13. Day 6 (12.00 hours). There were three (left) and four (right) implantation swellings in the horns. The section, which was incubated for SDH after removal of lipids, was cut at an angle which was slightly tangential to the implanted blastocyst, and includes the centro-lateral and most of the mesometrial endometrium. The strong supranuclear activity in the luminal epithelium (left) becomes progressively weaker as the epithelium starts to break down at the edge of the decidualized area. In the differentiated decidual cells around the implantation site, activity is strong; in the less differentiated cells at the bottom, it is rather weak; in the mesometrial stromal cells, it is moderate. No reaction was seen in the nuclei. $\times 85$.

FIG. 14. A neighbouring section to that in Fig. 13 after incubation for AMPase. The strongest reaction appeared in the same area of decidual cells which also showed the strongest SDH activity, but the reaction was at the cell borders (the depth of focus partly obscures this in places). Control sections incubated with glycerophosphate suggested that some of this reaction may be non-specific. Specific $5^{\prime}$-nucleotidase in the luminal borders of the epithelium can be seen to be weakening as the epithelium breaks down within the implantation area. $\times 85$.

FIG. 15. Day 7 (11.00 hours). There were seven swellings in each horn. The section was cut at the level of an implanted embryo and incubated for $\mathrm{LDH}$ after removal of lipids. In the antimesometrial half, the reaction for $\mathrm{LDH}$ is strong over a large area of the decidua. Around this is a zone of weak activity but in a narrow zone at the edge of the decidua, the cells gave a stronger reaction. The peripheral, non-decidualized stromal cells and those in the mesometrial quadrant gave very weak reactions. The activity is still strong in the glandular epithelium and the intact luminal epithelium. $\times 21$.

FIg. 16. The same section as in Fig. 15. Part of the antimesometrial endometrium, showing the cytoplasmic location of the reaction. $\times 85$.

FIG. 17. The same section as in Fig. 15, showing the weak activity in the stromal cells in the mesometrial quadrant, the stronger reaction in the capillary endothelium, and the very strong activity in the decidual cells (right) and the luminal epithelium and residual glands. $\times 85$.

Fig. 18. The same uterus as in Figs 15 to 17, at approximately the same level, stained by the PAS technique, showing the major distribution of glycogen. $\times 85$. 
cells around it. The primary decidua was still LDH- and SDH-active and APase-free but in the differentiating secondary decidua, a strong APase reaction extended antimesometrially and laterally half-way to the endometrial/ myometrial border. There was an inverse relationship between APase and AMPase, APase-active decidual cells showing almost no AMPase, while the non-decidualized cells of the peripheral and mesometrial stroma were AMPaseactive and APase-inactive. A few of the glycogen-loaded cells of the primary decidua gave reactions with AMP substrate, but this appeared to be due to a non-specific phosphatase. The increase in reactions for cytoplasmic LDH and $\mathrm{SDH}$ had spread into the secondary decidua and the reactions were stronger than at the earlier stages, but the area of increased activity was much smaller than that of APase, though larger than the area of glycogen-loaded cells. The LDH- and SDH-enriched cells contained much less lipid than those of the remainder of the decidualizing stroma, and most had completed their mitotic division.

\section{Day 6}

Plate 2, Figs 8 to 12 show the implantation site in the uterus of a mouse killed at 10.20 hours on Day 6. The area of APase activity can be seen in Pl. 2, Fig. 8. In the endometrium, only the peripheral stroma, luminal and glandular epithelia and capillary endothelium remain inactive. Plate 2, Figs 9 and 10 reveal a considerable increase in LDH in differentiated decidual cells around the implantation site over an area which is still much smaller than that giving APase reactions, and larger than the glycogen-loaded zone around the conceptus. The remainder of the antimesometrial endometrium, and that of the whole mesometrial quadrant, show no increase in activity. The section in Pl. 2, Fig. 11 shows that strong reactions for AMPase have now appeared at the surfaces of the decidual cells over an area larger than that of increased LDH (Pl. 2, Fig. 9) and almost as large as the APase-reactive area in Pl. 2, Fig. 8. It is possible that not all of this reaction indicates specific 5'-nucleotidase, however, for substitution of glycerophosphate for AMP in the incubation mixture ( $\mathrm{pH} \mathrm{6.5)} \mathrm{also}$ produced a fairly strong reaction in many of these cells. A small band of nonreactive cells has appeared around the luminal epithelium mesometrial to the decidua. The reaction in the remainder of the mesometrial stromal cells, and those in the peripheral endometrium, is thought to be that of specific 5'nucleotidase.

In PI. 3, Figs 13 and 14, adjacent sections of another decidual swelling are illustrated, cut across the implantation site, and incubated for SDH (Pl. 3, Fig. 13) and AMPase (Pl. 3, Fig. 14). The area of decidualizing cells giving increased reactions for SDH correlates closely with that in which AMPase has appeared. As the luminal epithelium breaks down on entry into the implantation site, both SDH and AMPase can be seen to weaken and disappear. Paired sections, incubated for $\mathrm{LDH}$ and SDH, from the uteri of a number of mice killed on Day 6 were compared. At this stage, it seemed that increased reactions for SDH were given by cells covering a greater area of the decidua than those for $\mathrm{LDH}$, and that the stromal cells of the mesometrial quadrant gave stronger reactions for SDH than for $\mathrm{LDH}$. The epithelium of the peripheral residual 
glands showed strong LDH, SDH and AcPase, but no AMPase or APase. The endothelium of the vascular channels within the decidua showed weak $\mathrm{SDH}$ and LDH, no APase or ATPase and no PAS-reactive basal laminae. The glycogenrich cells around the implanted embryo contained phosphorylase, but this appeared to be of low activity. Except in the peripheral zone, lipid droplets were plentiful throughout the endometrium.

\section{Day 7}

Sections through decidua on Day 7 are illustrated in Pl. 3, Figs 15 to 18 . Only a very narrow zone of peripheral stroma remains non-decidualized over the antimesometrial and lateral aspects. These stromal cells were APaseinactive, AMPase-active, gave very weak reactions for $\mathrm{SDH}$ and $\mathrm{LDH}$, contained glycogen and phosphorylase but were almost devoid of lipid droplets. Within this zone, the glandular epithelium showed no diminution of LDH or $\mathrm{SDH}$, especially in the supranuclear cytoplasm which was relatively free of lipids, but APase, AMPase, phosphorylase and glycogen were not located. Some glands were seen, sectioned longitudinally, entering the decidualized area, becoming attenuated with flattening of their epithelial cells, but retaining their dehydrogenase activities until their final disappearance. In the mesometrial quadrant, the luminal epithelium at the border of the decidua was still SDHand AMPase-active, but APase-inactive. The mesometrial stromal cells were now APase-active and, except for a subepithelial 'collar' of inactive cells, retained their AMPase activity. The stroma in the whole of the mesometrial quadrant was conspicuous for the very weak LDH activity of its cells (Pl. 3, Fig. 17): its capillaries were prominent because of the stronger LDH reactions of their endothelium. Within the decidua, the increase in both $\mathrm{LDH}$ and SDH had extended antimesometrially and laterally, covering an area almost the same as that of newly acquired AMPase reactivity, but still smaller than that of strong APase activity. Glycogen could not be demonstrated in the LDHenriched antimesometrial decidual cells. The heavy deposits of glycogen in the cells mesometrial and lateral to the embryo (the 'glycogen wings'-Christie, 1967) were not accompanied by very strong LDH activity. Lipid material had almost disappeared from the most strongly LDH- and SDH-active cells but at the edge of this active area there was a zone of very weak LDH (Pl. 3, Fig. 15) and SDH and a heavy lipid content. Outside this lipid zone, there was always a narrow band of cells which reacted more strongly for both dehydrogenases than did the cells on either side (Pl. 3, Figs 15 and 16). The distribution of phosphorylase was apparently identical with that of glycogen, but less correlation was found between glycogen (Pl. 3, Fig. 18) and LDH. Vascular channels within the decidua showed very little endothelial $\mathrm{LDH}$ or $\mathrm{SDH}$, no APase or ATPase and no PAS reactivity of their basal laminae.

During Day 8, no significant alterations in the pattern of enzymatic changes appeared.

\section{Localization of $\mathcal{N} A D$ diaphorase}

The distribution and the changes in the depth of colour obtained showed close correlation with those for $\mathrm{LDH}$ at each stage of pregnancy examined. 


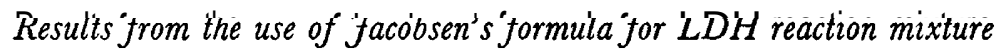

The time needed to produce optimum colour reactions was about $5 \mathrm{~min}$, and the localization and pattern of changes were identical with those obtained in the standard incubation mixture.

\section{Addition of $10^{-3 \cdot 25} \mathrm{M}-u r e a$ and $10^{-4} \mathrm{M}-$ pyruvate to the reaction mixture}

Urea greatly reduced the reactions in all the tissue components of the endometrium, but the low concentration of pyruvate was without effect.

\section{DISCUSSION}

The similarity between the patterns of the reactions obtained with the standard reaction mixture for $\mathrm{LDH}$ and those for NAD-diaphorase might suggest that the former technique could be revealing activity of the diaphorase system rather than that of LDH. Jacobsen's incubation mixture, however, produced identical distribution patterns to those from the standard solution. Since Jacobsen'S formula includes exogenous PMS as an electron acceptor, and the shorter incubation time should limit diffusion, it may be argued that this makes the reaction independent of endogenous diaphorase and that both techniques are revealing the activity of the dehydrogenase.

Of all the parameters examined, the earliest change in the future implant $=$ tion areas appeared to be the loss of ATPase from a localized group of lateroantimesometrial subepithelial capillaries, and of AMPase from stromal cells in the same area, although the exact time of onset is difficult to determine. Both processes had already started before the first leakage of Pontamine blue could be recognized. In earlier experiments on pseudopregnant mice (Hall, 1969), endothelial ATPase and PAS reactivity of the basal laminae had already dis appeared from subepithelial capillaries in deciduomata $21 \mathrm{hr}$ after an inductive intrauterine injection of oil at 15.00 hours on Day 4. The changes must, there fore, have been initiated earlier, probably at the time when sensitivity to Pontamine blue was not yet demonstrable in pregnant mice. If, as Campbell (1968) suggested, endothelial ATPase is involved in the metabolism of the mucopolysaccharides of basal laminae, one might postulate that the rise in oestrogen which precedes implantation produces increased capillary pe meability by lowering ATPase to a level at which integrity of the basal laminae cannot be maintained. This would be reflected experimentally in the local escape of Pontamine blue and physiologically would permit the passage of add 7 tional electrolytes, nutrients and substrates between blood and tissue cells at the decidual sites. Yochim \& Mitchell (1968) measured intrauterine oxygen tension in the rat uterus during early pregnancy, and found local changes during nidation. They concluded from their experiments that a major site for oxygen diffusion is the subepithelial capillary bed on the antimesometrial side of the uterus and that this might provide specificity for the site but not the timing of nidation. These are the vessels in which the changes in ATPase activity and PAS reactivity first appear in the mouse.

The first appearance of increased LDH in the APase-free cells of the primary decidua was a little in advance ofthat of demonstrable glycogen, phosphorylase 
and increased AcPase in the same cells, and of APase in the cells of the differentiating secondary decidua, all of which could be detected while the unimplanted blastocyst was still in contact with an intact epithelium. In the secondary decidua, the spread of APase advanced ahead of all the other changes except for the loss of AMPase (specific 5'-nucleotidase) and of capillary ATPase, and showed no correlation with the distribution of glycogen or lipid. In the secondary decidua also, reactions for $\mathrm{LDH}$ strengthened at the time when glycogen synthesis in the same cells was giving place to glycolysis but, in the primary decidua, heavy glycogen deposition and strong LDH were present simultaneously.

Jacobsen (1969) and McMillan \& Wittum (1971) showed that, in histochemical tests for LDH, those cells in which the reaction is most inhibited by 3.4 or 4 mol urea contain the greatest amount of M-subunits. Yochim (1971) and Yochim \& Clark (1971a) reported that, in the uterine endometrium of the rat, 80 to $90 \%$ of the total LDH as revealed by biochemical techniques consists of M-type subunits, H-subunits contributing the rest. This predominance of $\mathrm{M}$-subunits is apparently true for the mouse also, since addition of urea produced marked inhibition whereas low concentrations of pyruvate did not. The high proportion of $\mathrm{M}-\mathrm{LDH}$ would enable the tissues to derive energy from anaerobic pathways when oxygen is deficient (Yochim, 1971). Yochim \& Clark (1971b), again using biochemical techniques, found that the rise in LDH after implantation in the rat favoured the $\mathrm{H}$-subunits at the expense of the M-type, and that there was a direct relation between intrauterine $P_{\mathrm{O}_{2}}$ and percentage $\mathrm{H}$-subunits. The percentage changes were not large and would probably be difficult to demonstrate by histochemical techniques alone. It is not surprising that, so far, the present tests have provided no information on this point for the mouse.

It may be relevant here to point out that Surani \& Heald (1970) challenged Yochim \& Mitchell's (1968) view that, during nidation in the rat, uterine metabolism shifts from an anaerobic pattern to one of aerobiosis. Their own experiments on rats indicated that the reverse is true and that the oxygen supply to the decidual tissue is more likely to be reduced at these early stages. They relate the increased capacity for anaerobic metabolism to the storage of glycogen in the decidualizing cells which occurs at this time.

The distributions of SDH and $\mathrm{LDH}$ in the endometrium were similar, as also were the sites and time relations of increases in their activity. Only minor differences in the general levels of activity of the two enzymes were noted, reactions for $\mathrm{SDH}$ being weaker in the luminal epithelium and stronger in the non-decidualized stromal cells than those for LDH. Wong \& Dickson (1969) also found similar distribution patterns and levels of activity of the two enzymes in a histochemical study of the mouse endometrium.

Although some of the reaction with AMP substrate which appeared in the decidual cells after implantation was possibly catalysed by a non-specific phosphate-splitting enzyme, there seems no doubt that an AMPase is preferentially involved. The alternate lowering and raising of the activity of this enzyme would produce fluctuations in the level of AMP in these cells which might affect the amount of phosphorylase activity available for glycolysis. The 
histochemical technique used for phosphorylase, providing, as it does, exogenous AMP, demonstrates total phosphorylase activity and does not localize phosphorylase $a$. The rise and fall of glycogen and the accompanying changes in activity of the various enzymes in the antimesometrial decidua make this a highly metabolic tissue, with rapid turnover of glycogen during Days 5 and 6 with glycolysis in the ascendant on Day 7. The accumulation of glycogen in the glycogen wings on Day 7 , not accompanied by marked changes in $\mathrm{LDH}$, suggests that this is an area of glycogen storage at this time.

Wong \& Dickson (1969) accepted the opinion of Hitzeman (1963) that lipids stain pink when Nitro-BT is the electron acceptor in dehydrogenase techniques, and used this as their criterion for identification of lipids in the mouse uterus. The current tests do not support this for uterine tissue, but are in agreement with the conclusions of Wattenburg (1958), Novikoff (1959) and Karaki (1970) that, in addition to the purple reaction indicating specific activity, there is non-specific deposition of dark blue granules of dinitroformazan onto each lipid droplet or at the lipid-aqueous interface, which is not an indication of increased dehydrogenase activity. This is supported in the present tests in which the navyblue formazan granules precipitated onto the Oil Red-stained lipid droplets, the two substances having identical distribution patterns. Indeed, the blue granular deposit proved a valuable indicator of the first appearance and early distribution of the lipids, but the increasingly heavy precipitation as lipid deposition increased tended to obscure the specific Nitro-BT-reductase reaction. This was overcome by immersing the sections for $10 \mathrm{~min}$ in cold acetone before incubation (Novikoff, 1959; Karaki, 1970) which successfully removed the lipids without altering the distribution levels of the specific reactions.

Beall \& Werthessen (1971), using extraction methods, found that triglycerides accumulated in uterine tissue of the rat shortly before implantation, increased during Day 6 and were depleted from implantation areas by Day 7. They concluded from their experiments that the rat utilizes endometrial fatty acids esterified to triglyceride. No acceptable histochemical technique seems to be available for triglycerides. It is evident, however, that Oil Red-stainable neutral lipids in implantation areas of the mouse uterus during early pregnancy follow a metabolic pattern similar in timing to that of triglycerides in the rat, accumulating before implantation in the subepithelial stroma around the blastocyst, spreading through the decidua during Days 5 and 6 and disappearing from the centre outwards during Days 6 and 7. Although both lipid and glycogen were often detected in the same cells, lipid-rich cells in general contained little glycogen, and the strongest reactions for $\mathrm{LDH}$ and SDH usually occurred in cells depleted of lipids.

\section{ACKNOWLEDGMENTS}

This work was supported by a grant from the Agricultural Research Council, to whom I am indebted. I have pleasure in acknowledging the technical assistance of Mrs J. Muspratt and Miss P. Sharman. Some of the techniques for $\mathrm{LDH}$ were carried out by $\mathrm{Mr} \mathrm{W}$. M. Webb as part of his undergraduate research project. 


\section{REFERENCES}

BARRon, K. D. \& Boshes, R. (1961) Histochemical demonstration of 5-nucleotidase in the central nervous system. Effects of manganous ions and pH. F. Histochem. Cytochem. 9, 455.

BeAll, J. R. \& Werthessen, N. T. (1971) Lipid metabolism in the rat uterus after mating. F. Endocr. $51,637$.

Burstone, M. S. (1962) Enzyme histochemistry and its application in the study of neoplasms. Academic Press, New York.

CAMPBELL, W. G. (1968) Localization of adenosine 5'-triphosphatase in vascular and cellular synovium of rabbits. Lab. Invest. 18, 304.

Christie, G. A. (1966) Implantation of the rat embryo: glycogen and alkaline phosphatases. $\mathcal{F}$. Reprod. Fert. 12, 279.

Ghristie, G. A. (1967) Implantation of the rat embryo: further histochemical observations on carbohydrate, RNA and lipid metabolic pathways. F. Reprod. Fert. 13, 281.

Clark, S. W. \& YochIm, J. M. (1971) Lactic dehydrogenase in the rat uterus during progestation, its relation to oxygen tension and the regulation of glycolysis. Biol. Reprod. 5, 152.

Gomori, G. (1952) Microscopic histochemistry, principles and practice. University of Chicago Press, Chicago.

HALL, K. (1968) Disappearance of histochemically-demonstrable adenosine triphosphatase and of PAS-reactive basement membranes in blood vessels in the decidua during ovum implantation in mice. 7 . Endocr. 41, 53.

HALL, K. (1969) Uterine mitosis, alkaline phosphatase and adenosine triphosphatase during development and regression of deciduomata in pseudopregnant mice. F. Endocr. 44, 91.

HALl, K. (1971) 5'-Nucleotidase, acid phosphatase and phosphorylase during normal, delayed and induced implantation of blastocysts in mice: a histochemical study. 7. Endocr. 51, 291.

Hitzeman, J. W. (1963) Observations of the subcellular localization of oxidative enzymes with Nitro Blue Tetrazolium. F. Histochem. Cytochem. 11, 62.

JACOBSEN, N. O. (1969) The histochemical localization of lactic dehydrogenase isoenzymes in the rat nephron by means of an improved polyvinyl alcohol method. Histochemie, 20, 250.

Karaki, S. (1970) Observations on the use of Nitro Blue Tetrazolium in the detection of early myocardial changes. Histochem. 7. 2, 453.

McMrLxan, P. J. \& Wittum, R. L. (1971) Lactic acid dehydrogenase isoenzymes of rat soleus muscle fibers as demonstrated by histochemical staining and electrophoresis. F. Histochem. Cytochem. 7, 421.

Novikofr, A. B. (1959) Enzyme cytochemical pitfalls in the current use of the tetrazolium technique. 7. Histochem. Cytochem. 7, 301 .

Pearse, A. G. E. (1960) Histochemistry, theoretical and applied, 2nd edn. Churchill, London.

PEArse, A. G. E. (1968) Histochemistry, theoretical and applied, Vol. 1, 3rd edn. Churchill, London.

Pearse, A. G. E. (1972) Histochemistry, theoretical and applied, Vol. 2, 3rd edn, p. 1326. Churchill, London.

Surani, M. A. H. \& Heald, P. J. (1970) The metabolism of glucose by rat uterus tissue in early pregnancy. Acta endocr., Copenh. 66, 16.

TAKeuchi, T. \& Kuriaki, H. (1953) Histochemical detection of phosphorylase in animal tissues. 7. Histochem. Cytochem. 3, 153.

Wachstein, M. \& MEISEL, E. (1956) Histochemistry of substrate specific phosphatases at a physiological pH. 7. Histochem. Cytochem. 4, 424.

Wachstein, M. \& Mersed, E. (1957) Histochemistry of hepatic phosphatases at a physiological pH. 7. Histochem. Cytochem. 27, 13.

WATtenburg, L. W. (1958) Microscopic histochemical demonstration of steroid-3 $\beta$-dehydrogenase in tissue sections. F. Histochem. Cytochem. 6, 225.

Wong, Y. C. \& Dickson, A. D. (1969) A histochemical study of ovoimplantation in the mouse. F. Anat. $105,547$.

Үоснім, J. M. (1971) Intrauterine oxygen tension and metabolism of the endometrium during the preimplantation period. In: Biology of the Blastocyst, p. 363. Ed. R. J. Blandau. University of Chicago Press, Chicago.

Yochim, J. M. \& GraRk, S. W. (1971a) Lactic dehydrogenase activity in the uterus of the rat during the estrous cycle and its relation to intrauterine oxygen tension. Biol. Reprod. 5, 146.

Yochim, J. M. \& CLARK, S. W. (1971b) Lactic dehydrogenase in the rat uterus during progestation, its relation to intrauterine oxygen tension and the regulation of glycolysis. Biol. Reprod. 5, 152.

Yоснім, J. M. \& Mrtchell, J. A. (1968) Intrauterine oxygen tension in the rat during progestation: its possible relation to carbohydrate metabolism and the regulation of nidation. Endocrinology, 83, 706. 